\title{
Vitamin C, Grape Seed Extract and Citrus Bioflavonoids Protect the Skin against Photoaging: A Review
}

\author{
Brett J. West ${ }^{1 *}$, Shixin Deng1, 'Afa Kehaati Palu² \\ ${ }^{1}$ Research and Development, New Age Beverages, American Fork, Utah, USA \\ ${ }^{2}$ Research and Development, Ariix/Zennoa, American Fork, Utah, USA \\ Email: *brett_west@newage.com
}

How to cite this paper: West, B.J., Deng, S. and Palu, A.K. (2020) Vitamin C, Grape Seed Extract and Citrus Bioflavonoids Protect the Skin against Photoaging: A Review. Journal of Biosciences and Medicines, 8, 116-134.

https://doi.org/10.4236/jbm.2020.812012

Received: November 14, 2020

Accepted: December 19, 2020

Published: December 22, 2020

Copyright $\odot 2020$ by author(s) and Scientific Research Publishing Inc. This work is licensed under the Creative Commons Attribution International License (CC BY 4.0).

http://creativecommons.org/licenses/by/4.0/

(c) (i) Open Access

\begin{abstract}
The skin is a major protective organ of the body. It is constantly exposed to the environment and is very resilient. But exposure to ultraviolet (UV) rays from the sun results in the production of reactive oxygen species (ROS) and subsequent inflammatory responses that can overwhelm the innate protective mechanisms of the skin. This results in damage and premature aging. Strategies to mitigate this premature photoaging might include avoidance of sunlight. However, some sunlight exposure is beneficial to health. One notable example of this is the production of vitamin D. A more practical approach to preventing adverse effects of UV light in the skin is antioxidant supplementation. Dietary antioxidants may help control ROS propagation following UV light exposure. To further evaluate the utility of antioxidants in protecting the skin, in vitro, in vivo and human studies of three well known dietary antioxidants are reviewed and discussed. The data clearly demonstrate that vitamin C, grape seed extract and citrus bioflavonoids have the potential to reduce the damaging effects of excess sun exposure via antioxidant, anti-inflammatory and immunomodulating mechanisms. As such, regular ingestion of dietary antioxidants appears to be a useful strategy for protecting the skin against photoaging.
\end{abstract}

\section{Keywords}

Photoaging, Skin, Antioxidants, Vitamin C, Grape Seed Extract, Citrus Bioflavonoids

\section{Introduction}

Photoaging, also known as actinic aging, is the accelerated or premature aging of the skin by ultraviolet (UV) light from the sun [1]. The effects of sun exposure 
can be easily observed among people who have spent a large amount of time outdoors. Characteristics of long-term excessive sun exposure include increased skin wrinkling, lentigines (areas of hyperpigmentation), dyschromia, uneven skin tone, sagging skin, sallow appearance, rough texture, increased telangiectases, purpura and actinic keratosis [2].

UVB rays $(280-315 \mathrm{~nm})$ do not penetrate beyond the most upper layers of the skin, such as the epidermis. Even so, UVB is very biologically active and is associated with the development of sunburn, photoaging and skin cancer. UVA rays $(315-400 \mathrm{~nm})$ penetrate much further into the dermis and are also associated with photoaging and cancer, as well as tanning [3] [4]. One distinctive feature of photoaged skin is solar elastosis, an accumulation of degraded elastin that is not typically found in chronologically aged skin [5]. The resulting loss of skin elasticity contributes to the leathery and sagging appearance of photoaged skin. Degradation of the collagen in the extracellular matrix is a major aspect of chronological aging of the skin. These collagen structural alterations decrease skin strength and resiliency, thereby increasing wrinkle formation [6]. During photoaging, this collagen degradation is accelerated even further with very noticeable effects on skin quality [7] [8].

The underlying mechanisms of photoaging begin with UV-induced generation of reactive oxygen species (ROS). UV light excites skin cell chromophores in the presence of molecular oxygen thereby producing ROS such as superoxide anion radicals (SAR), hydroxyl radicals and hydrogen peroxide [9]. When endogenous antioxidant mechanisms are overwhelmed by excessive UV exposure, ROS initiate a cascade of cellular signals leading to the transcription of matrix metalloproteinases (MMPs) in fibroblasts [10]. This signal cascade also leads to an influx of elastase producing neutrophils [11]. Increased MMP and elastase activity leads to deleterious changes in the extracellular matrix that are behind the appearance of wrinkling, sagging, and other structural changes in the skin. ROS generation also mediates a host of other mechanisms that lead to the other salient features of photoaging, including hyperpigmentation and dryness [12].

Avoidance of sunlight and topical sunscreen agents may help reduce exposure to excessive UV irradiation. However, some sun exposure is necessary for optimal health. For example, UV light is necessary for vitamin D synthesis in the skin [13]. Another approach to mitigating the adverse effects of UV light in the skin is antioxidant supplementation. Dietary antioxidants may help control ROS propagation when excessive UV exposure overwhelms endogenous antioxidant systems [14]. This review discusses the findings of in vitro, in vivo and human studies of three well known antioxidants as they relate to protection against photoaging. These three antioxidant substances are vitamin C, grape seed extract and citrus bioflavonoids.

\section{Vitamin C}

\subsection{Background}

In 1912, Casmir Funk coined the term "vitamine", later changed to "vitamin", 
and postulated the existence of vitamin C [15]. This vitamin, known as ascorbic acid, is required for normal growth and many physiological functions [16] [17] [18] [19] [20]. It also possesses anti-aging, anti-inflammatory, and photoprotective properties [21] [22] [23]. Vitamin C is necessary for collagen, neurotransmitter and carnitine biosynthesis. It also promotes keratinocyte differentiation, limits melanogenesis, inhibits MMP activity, is involved in protein metabolism and immune system activity [17] [24]-[31].

It's estimated that the average adult has an ascorbic acid reserve, or pool, of 1.2 to 2.0 grams throughout the body. Should all sources of vitamin $\mathrm{C}$ be eliminated from a person's diet, this ascorbic acid pool will be depleted within 4 to 12 weeks [19] [30] [31] [32]. Consequently, vitamin C-mediated metabolic processes would be greatly disrupted and health severely impacted. Vitamin C deficiency may result in several health conditions, most notably scurvy. This disease was first reported in 1550B.C. Later, Hippocrates described it as follows, "the mouth feels bad; the gums are detached from the teeth; blood runs from the nostrils... ulcerations on the legs; some of these heal... skin is thin." In the 1700s, James Lind discovered that those suffering from scurvy were cured when they consumed lemons and oranges [19]. Low plasma vitamin C levels are also associated with atopic dermatitis (AD) and porphyria cutanea tarda [16] [17]. In fact, vitamin C is vital to maintaining skin health in general. Its role in protecting the skin against UV-induced damage is likewise important.

\subsection{In Vitro Studies}

UVA and UVB-induced declines in collagen biosynthesis within skin fibroblasts were prevented by incubation with ascorbic acid. Further, ascorbic acid limited ROS generation, improved antioxidant capacity and restored endocannabinoid receptor expression in these fibroblasts [33]. The effect of vitamin C on expression of MMP and tissue inhibitors of metalloproteinases (TIMP) in human dermal fibroblasts was investigated. Following UVA irradiation, MMP-1 and MMP-2 gene expression and activities were significantly reduced in fibroblasts cultured with vitamin C. However, vitamin C did not influence TIMP expression [24]. In a separate study, UVA-induced lipid peroxidation in human keratinocytes (as measured by malondialdehyde concentration) was inhibited by ascorbic acid in a concentration-dependent manner. Cell membrane damage was also decreased by $45 \%$ in keratinocytes cultured with ascorbic acid, thus demonstrating significant protection via antioxidant mechanisms [34].

Pretreatment of $\mathrm{HaCaT}$ cells with ascorbic acid reduced the UVA-induced DNA damage that was accelerated by phototoxic antidiabetic drugs, specifically bendroflumethiazide, furosemide, glibenclamide, glipizide, tolbutamide or trichloromethiazide [35]. These in vitro studies demonstrate the potential of vitamin $\mathrm{C}$ to prevent oxidative cellular damage induced by UV light. Further, vitamin $\mathrm{C}$ can inhibit the in vitro expression of proteolytic enzymes that are re- 
sponsible for collagen and elastin degradation and eventually breakdown the extracellular matrix.

\subsection{In Vivo Studies}

Significant declines of ascorbate levels in the epidermis and dermis of hairless mice occur after excessive UV exposure, indicating that ascorbic acid is consumed in the antioxidant defense of the skin [36]. This was confirmed by an experiment wherein hairless mice fed a diet supplemented with vitamin $\mathrm{C}$ experienced pronounced and statistically significant reductions in malignant skin tumor incidence, when compared to control animals, following 15 weeks of UV light exposure [37].

Freshwater carp (Catla catla) larvae were fed a diet supplemented with vita$\min \mathrm{C}$ for 40 days. Afterwards, they were exposed to substantial UVB irradiation doses. When compared to fish in a control group, those fed vitamin $C$ experienced greater survival rates and weight. Vitamin $\mathrm{C}$ supplemented fish larvae also had higher nitric oxide synthase and lower thiobarbituric acid reactive substances (TBARS, a marker for oxidative damage). They also had lower DNA fragmentation in tissue samples [38].

\subsection{Human Studies}

The best studied use of vitamin $\mathrm{C}$ for photoprotection is as a topical agent. A Bayesian meta-analysis of 31 clinical trials involving 741 Chinese and Caucasian subjects found that topical vitamin $\mathrm{C}$ was effective in reducing UV light-induced pigmentation in a dose dependent manner [21]. The clinical trials revealed that vitamin $\mathrm{C}$ was effective in preventing pigment formation, rather than removing existing melanin which is coherent with its antioxidant properties. Even though oral dosing of vitamin $\mathrm{C}$ was not the focus, this meta-analysis does demonstrate the ability of vitamin $\mathrm{C}$ to protect against photoaging of the skin. Furthermore, increased dietary intake of vitamin $\mathrm{C}$ has been shown to result in significant rises in both plasma and skin vitamin $\mathrm{C}$ content [39].

After 4 weeks, ingestion of $100 \mathrm{mg}$ vitamin C/day significantly increased radical scavenging activity in the skin, measured by electron paramagnetic resonance spectroscopy, by $22 \%$ above that of a placebo group. Additional analysis revealed that maximum radical scavenging activity was reached within two weeks [40].

In healthy volunteers, ingestion of vitamin $\mathrm{C}$, combined with vitamin $\mathrm{E}$, for 8 days increased the minimum erythemal dose (MED) of UV light from 80 to 96.5 $\mathrm{mJ} / \mathrm{cm}^{2}(\mathrm{p}<0.01)$ while the MED decreased from 80 to $68.5 \mathrm{~mJ} / \mathrm{cm}^{2}$ in those who consumed a placebo [41]. The increased threshold for UV energy required to initiate erythema demonstrates that the antioxidant vitamins inhibited the initiation of ROS production in the skin. The oral intake of vitamins $\mathrm{C}$ and $\mathrm{E}$ for three months significantly reduced the sunburn reaction to UVB irradiation in healthy volunteers. Additionally, UV-induced thymine dimers (DNA damage) in the skin were decreased following vitamin supplementation [42]. 


\section{Grape Seed Extract}

\subsection{Background}

Grapes (Vitis vinifera) are one of the most widely consumed fruits in the world and have a very long history of human food use. During the processing of grapes for juice and wine, the seeds are discarded. An extract produced from the seeds is rich in polyphenolic compounds, especially proanthocyanidins (condensed tannins). In addition to cyanidin-3-glucoside, the extract includes gallic, protocatechuic, chlorogenic, caftaric, caffeic and trans-coutaric acids as well as ellagic acid, quercetin, kaempferol, luteolin and dihydrofisetin derivatives [43]. The oligomeric and polymeric procyanidins in grape seed are composed of catechins, procyanidin dimers, epicatechin gallate, procyanidin dimer gallates, procyanidin dimer digallates, procyanidin trimers, and procyanidin trimer gallates [44].

Grape seed extract has notable cardiovascular system benefits. Meta-analyses of clinical trials have revealed that it helps control blood pressure (with as little as $100 \mathrm{mg}$ /day), fasting plasma glucose, total cholesterol, LDL cholesterol, triglycerides and C-reactive protein [45] [46]. Grape seed extract may also provide other positive effects on human health through its anti-inflammatory, immune modulating and antimicrobial properties, to name just a few [47]. But the most salient feature of grape seed extract is its powerful antioxidant action [48]. Its exceptional antioxidant activity is a major factor in the anti-photoaging properties of grape seed extract.

\subsection{In Vitro Studies}

Human keratinocytes were cultured with or without grape seed extract for 30 minutes prior to UVB irradiation. Cells that were pre-treated with grape seed extract experienced increased cell viability, lower lipid peroxide levels (or less oxidative damage) and fewer DNA photolesions [49]. In another study, grape seed extract also decreased the level of ROS in UVB-irradiated human keratinocytes in vitro. Further, NF-kB p65 protein levels, a marker of inflammatory signaling, increased in untreated cells following UVB exposure. But NF-kBp65 remained at pre-UVB exposure levels in cells cultured with grape seed extract [50].

DNA repair was significantly increased in xeroderma pigmentosum complementation group A (XPA)-proficient human fibroblasts that were cultured with grape seed proanthocyanidins (GSPs) for 3 hours while simultaneously being exposed to UVB light. GSPs further enhanced nuclear translocation of the XPA protein and increased its interactions with ERCC1, a DNA excision repair protein [51]. These in vitro experiments demonstrate that GSP is not only capable of curbing the initiation stage of photodamage, by inhibiting ROS formation and inflammation, but may also amplify DNA repair mechanisms in skin cells.

\subsection{In Vivo Studies}

Feeding of GSPs inhibited of UV-induced cyclooxygenase-2 (COX-2) expression, prostaglandin synthesis, leukocyte infiltration and myeloperoxidase induc- 
tion in the skin of SKH-1 hairless mice. Pro-inflammatory cytokines (TNF- $\alpha$, interleukin $1 \beta$ and IL-6) were also lower in the skin of GSP fed mice than in control mice [52]. Chronic inflammation involves elevated production of proteolytic enzymes which then degrade the extracellular matrix of the dermis [53]. As such, the anti-inflammatory action of GSPs will reduce the UV-induced degradation in skin quality that occurs with sun exposure.

Orally administered grape seed polyphenols decreased macrophage infiltration into and elastin degradation of aorta tissue as well as reduced expression of MMP-2 and MMP-9 [54]. The overall effect was to prevent excessive dilation of the aorta following repeated exposure to elastase. While this experiment did not directly involve UV irradiation of the skin, similar pathological processes were involved. And these results provide additional evidence of the ability of phytochemicals in grape seed extract to protect the structure and function of the extracellular matrix.

The addition of GSP to the diet of SKH-1 hairless mice for two weeks reduced tumor incidence, multiplicity and size after 30 weeks of UVB exposure to the skin. Biochemical analysis revealed significant reduction in lipid peroxidation, thus suggesting that the antioxidant activity of GSP is a major photoprotective mechanism [55]. Further, GSP ingestion maintained glutathione peroxidase, catalase, and glutathione levels while reducing hydrogen peroxide, lipid peroxidation, protein oxidation, and nitric oxide concentrations in the skin of UVB exposed mice. GSP also inhibited mitogen activated protein kinases (MAK) and nuclear factor $-\kappa \beta(\mathrm{NF}-\kappa \beta)$ signaling [56].

Additional research investigated the ability of GSP to prevent UVB-induced immunosuppression as another mechanism of protection against the development of skin cancer. In these studies, dietary GSPs mitigated UVB-induced suppression of dermal immune responses and increased IL-12 production. Intraperitoneal injection of a neutralizing anti-IL-12 antibody abolished the immune protective impact of GSP [57]. A GSP-enriched diet also counteracts UVB-stimulated immune suppression via IL-12 dependent activation of CD8+ effector T cells in mice [58]. From these results, it appears that antioxidant, anti-inflammation and immunomodulating activities all have some role in the photoprotective potential of grape seed extract in SKH-1 hairless mice.

Another line of anti-photoaging evidence involves melanogenesis. Feeding of grape seed extract to guinea pigs for 8 weeks resulted in less UV-induced skin pigmentation than that which occurred in control animals. This anti-melanogenic effect appears to involve antioxidant action as there was a decrease in ROS-related proliferation of melanocytes. Histology of the cells in the basal layer of the epidermis found fewer numbers of 3,4-dihydroxyphenylalanine-positive, 8-hydroxy-2'-deoxyguanosine (8-OHdG)-positive, Ki-67-positive, proliferating cell nuclear antigen (PCNA)-positive melanin-containing cells [59].

\subsection{Human Studies}

Japanese melasma (hypomelanosis) patients ingested proanthocyanidin-rich 
grape seed extract for 11 months, divided into two phases with a one-month break in treatment after the first 6 months. After the first phase of treatment, $83 \%$ of the participants experienced reductions in melasma intensity (lightening of dark spots), with 54\% experiencing continued improvement through the later 5 -month treatment phase. $\mathrm{L}^{*}$ values (lightening) significantly increased throughout the trial, with a corresponding significant decline in melanin index [60]. Sun exposure is a major factor in melasma. UV light is the primary causative agent that combines with other underlying factors to produce large areas of hyperpigmentation on the face. Since melasma is an excessive response to UV light exposure, ROS-mediated symptoms are reduced by dietary grape seed extract due to increased antioxidant capacity of the skin.

A 5-day clinical trial revealed that daily ingestion of grape seed extract increases serum total antioxidant activity. No such increase was observed in the placebo group [61]. The increase in serum antioxidant activity indicates that grape seed extract's protective effects occur not only in the skin but systemically. Again, photo damage is initiated by the production of ROS generation. Subsequent propagation of oxidative damage is attenuated by antioxidant action, and increased antioxidant activity in the serum directly translates to improved skin quality [62].

A few other clinical trials have been completed in which participants ingested dietary supplements containing grape seed extract (as low as $27.5 \mathrm{mg} /$ day) and other functional ingredients, such as vitamin $\mathrm{C}$ and zinc. These trials have included both men and women ( $\mathrm{n}=124$ in total) and have ranged from 56 to 180 days in length. In these studies, ingestion of supplements containing grape seed extract significantly increased collagen and elastic fiber density (both on the face and arm) as well as skin luminosity by $25.9 \%$. Significant improvements in erythema, skin hydration, skin radiance, overall appearance (including fine lines and wrinkles) and dermal ultrasound density were also evident. Mottled pigmentation of the skin was also significantly reduced [63] [64] [65] [66].

\section{Citrus Bioflavonoids}

\subsection{Background}

Citrus species are some of the most widely cultivated fruits in the world. Citrus fruit, juices, and processed compounds are major sources of nutrients in the human diet. Citrus is a well-known source of bioactive compounds, with flavonoids being major components [67]. Flavonoids are a large group of polyphenolic secondary metabolites widely occurring in plants. Flavonoids exhibit a wide range of biological activities. As such, they are usually called "bioflavonoids" [68] [69]. Flavonoids represent a group of low molecular weight phytochemicals with C6-C3-C6 carbon skeleton and are biosynthesized from derivatives of acetic acid/phenylalanine through the shikimic acid pathway [68] [70]. Hesperidin is reported to be the major flavonoid in orange and lemon [68] [71]. The bioflavonoids naringin, isonaringin and didymin are also found in different parts of various ci- 
trus fruits [72] [73]. Naringin and isonaringin were found to be the main flavonoid in fresh, oven-dried, and freeze-dried peels of grapefruit, an important cultivar of the Citrus genus [72]. Hesperidin is a $\beta$-7-rutinoside of hesperidin, with its aglycon of hesperidin bonded to rutinose [6-O-( $\alpha$-l-Rhamnopyranosyl)-d-glucopyranose] and/or [6-O-( $\alpha$-1-Rhamnosyl)-d-glucose], forming a disaccharide [68]. A wide range of biological and pharmacological activities have been reported for hesperidin [68] [74]. Citrus fruits and their flavonoids have potent anti-aging and photoprotective effects on the skin and could serve as powerful bioactive skincare agents [75].

\subsection{In Vitro Studies}

The effects of hesperidin on UVA-induced skin oxidative stress and inflammation, as well as the underlying mechanisms of action, were evaluated in human keratinocytes [76]. The results of this study indicated that hesperidin directly protects cells from UVA-induced cell damage. At $220 \mu \mathrm{g} / \mathrm{ml}$, hesperidin effectively protected $\mathrm{HaCaT}$ keratinocytes from UVA radiation-induced injury and significantly reduced UVA-induced oxidative stress and inflammatory response. These data indicate that hesperidin protects keratinocytes from both UVA- and UVB-induced damage and may involve anti-oxidative and anti-inflammatory activities. Consequently, the authors of this study suggested that hesperidin might be a useful sunscreen agent.

Hesperidin was also investigated for its ability to prevent apoptosis due to UVB-generated oxidative cellular stress. In this study, $76 \%$ of hesperidin treated human keratinocytes survived UVB exposure, a significantly greater survival rate than in untreated cells. Furthermore, hesperidin scavenged the 2,2-Diphenylpicrylhydrazyl (DPPH) radical in a dose-dependent manner [77]. In summary, the results indicate that hesperidin may scavenge ROS, absorb UVB irradiation and regulate apoptotic proteins, thus protecting human keratinocytes against UV damage. Additionally, we observed in our laboratory that a preparation of hesperidin-rich Citrus aurantium extract, combined with vitamin $\mathrm{C}$ and grape seed extract (Vináli), quite rapidly and thoroughly scavenged the DPPH radical.

The immune-modulatory activity of hesperidin was observed in multiple studies. When gavaged at $50 \mathrm{mg} / \mathrm{kg}$, hesperidin suppressed the production of the bacterial alpha-amylase antibody in mice [78]. The same dose of hesperidin was also found to increase the development of immunological memory in the cellular immune response. Treatment of UVA-irradiated human fibroblasts with $0.1 \%$ Citrus unshiu peel extract, containing hesperitin (an aglycon of hesperidin) was found to decrease expression of $\beta$-galactosidase, MMP-1, and the number of senescent cells [79]. In another study, pretreatment of human fibroblasts with hesperidin glucuronides provided $25 \%$ protection against UVA-induced necrotic cell death [80].

Naringenin and naringin, well-known antioxidants, have been shown to extend the life span and health of the Caenorhabditis elegans under normal condi- 
tions as well as during UVA-induced stress. This may be due to regulation of two stress-responsive genes (skn-1 and sir-2.1) and aging-regulating genes (daf-2 and age-1) [81]. Further, a synergistic anti-aging effect was observed when a combination of these compounds, in equal ratios by weight, were tested. Jung et al. studied on the effect of naringenin on UVB-induced matrix MMP-1 expression and its direct target [82]. Like all-trans retinoic acid, a US FDA approved anti-wrinkle drug, naringenin was found to significantly inhibit UVB-induced MMP-1 expression. This effect was further confirmed by an immunofluorescence experiment within the study.

Naringin decreases oxidative UVB radiation damage in NIH-3T3 cells and the associated inflammatory response by modulating PPAR- $\gamma$ expression. As such, it can effectively prevent UVB-mediated DNA damage, photoaging, and apoptosis [83]. In another in vitro assay, fresh and oven-dried grapefruit peel extracts displayed strong cytoprotective properties in SH-SY5Y neuroblastoma cell cultures at concentrations ranging from $0.1-0.25 \mathrm{mg} / \mathrm{ml}$ [72].

Didymin from citrus fruit was reported to reduce the effects of UV stress on nematodes ( $C$. elegans) by decreasing ROS levels and increasing superoxide dismutase (SOD) activity [84]. ROS levels are correlated with age-related phenotype. UV-induced bodily damage causes an increase in ROS levels. But didymin, at $0.1 \mathrm{mM}$, significantly reduced ROS accumulation in nematodes after UV irradiation.

Kim et al. isolated and identified a citrus flavonoid, 3,5,6,7,8,3',4'-heptamethoxyflavone (HMF), from citrus peels and investigated its potential for preventing photoaging [75]. The results of this study indicate that HMF inhibits collagenase activity, increases type I procollagen content in UV-induced HDFn cells and suppresses MMP-1 expression. In addition, HMF was found to affect the MAPK signaling pathway. These results suggest that HMF may possess photoprotective properties.

\subsection{In Vivo Studies}

Lee et al. investigated the anti-photoaging potential of hesperidin on dorsal skin in hairless mice [85]. Every day, six-week-old hairless male mice were administered $0.1 \mathrm{~mL}$ water containing hesperidin dosed at $100 \mathrm{mg} / \mathrm{kg}$ body weight. These animals were then exposed to UV light, and changes in skin wrinkle length and depth were measured. In the hesperidin-treated group, the average length and depth of wrinkles were significantly less than in the control group. The authors concluded that hesperidin's anti-photoaging effect involves preventing UV-induced increases in skin thickness, wrinkle formation and collagen fiber loss. Further, hesperidin may reduce expression of MMP-9 and pro-inflammatory cytokines.

Hesperidin was reported to decrease tryptophan intensity and interact with collagenase. It may inhibit metalloproteinases (collagenase, elastases, and hyaluronidases) by chelating their metal ions. Further, a face cream containing hespe- 
ridin nanoparticles (150 - $400 \mathrm{~nm}$ ) may reduce black circles in the under eye region. Additionally, daily topical application of a hesperidin nanoemulsion led to a significant skin whitening, reduction in trans-epidermal water loss, and inhibition of skin irritation after exposure to UV rays [86].

Immature Citrus unshiu powder (ICP) contains high concentrations of flavonoids such as hesperidin and narirutin. Ingestion of ICP increased epidermal cell growth, suppressed epidermal cell mortality and prevented basement membrane destruction in the skin of UVB irradiated hairless mice [87]. ICP also improved skin hydration and decreased transepidermal water loss. An SKH-1 hairless mouse model was also employed to study the anti-photoaging of naringenin in vivo [82]. In this model, the dorsal skin was exposed to UVB three times a week with the irradiation dose being increased weekly from 1 MED to 4 MED. The 4 MED UV dose was maintained until 15 weeks, after which skin surface impression were obtained and analyzed. During this study, the naringenin-treated group experienced significantly less MMP-13 expression. This inhibitory effect occurred mainly through the blockage of ERK2 kinase activity.

Martinez et al. applied a topical naringenin containing formulation to hairless mice to examine its potential for reducing UVB irradiation-induced skin inflammation and oxidative damage [88]. The topical application of the naringenin formulation protected mouse skin by inhibiting edema and cytokine production (TNF- $\alpha$, IL- $1 \beta$, IL-6, and IL-10).

In an experiment performed by Tirkey et al., hesperidin $(200 \mathrm{mg} / \mathrm{kg}$ daily) was found to protect against $\mathrm{CCl}_{4}$-induced oxidative stress in rats [89]. Hesperidin fed to mice also reduced superoxide generation in electron transfer and concerted proton transfer reactions [90]. A recent review of computational and experimental studies revealed that hesperidin, together with other flavonoids such as naringin, may outperform other drugs in COVID-19 prophylaxis and treatment clinical trials [91]. Hesperidin appears to have high binding affinity for the main cellular receptors of SARS-CoV-2 and possibly dampens excessive proinflammatory responses by the immune system. Hesperidin strongly inhibited rotavirus infectivity. Ingestion of hesperidin $(100 \mathrm{mg} / \mathrm{kg})$ also inhibited influenza A virus replication by up-regulating certain cell-autonomous immune responses.

\subsection{Human Studies}

A combination of citrus bioflavonoids and rosemary extract was evaluated for its photoprotective potential using human $\mathrm{HaCaT}$ keratinocytes as well as human volunteers. The combination of these two ingredients increased survival rates of $\mathrm{HaCaT}$ cells, following UVB irradiation, more than the individual extracts alone, suggesting potential synergic effects. The combination also decreased UVB-induced intracellular ROS and prevented DNA damage. It also decreased ex-vivo chromosomal aberrations in X-irradiated human lymphocytes isolated from the volunteers who had ingested it. After 8 weeks of consuming $250 \mathrm{mg}$ daily, the MED of the volunteers increased by $34 \%(\mathrm{p}<0.05)$ with a further $56 \%$ 
increase in protection after 12 weeks $(\mathrm{p}<0.01)$. The authors of this study suggested that ingestion of the combined extracts may be an alternative treatment to topical sunscreen application [92].

Exposure to UV light leads to skin inflammation. A systematic review and meta-analysis of randomized controlled clinical trials (RCTs) was conducted by Lorzadeh et al. to evaluate the effect of hesperidin supplementation on inflammatory markers [93]. The authors used a random-effects model to examine the differences in inflammatory markers between hesperidin supplementation and a control group. With 296 participants included in the study, the analysis showed that hesperidin supplementation significantly decreased vascular cell adhesion molecule 1 (VCAM-1) levels. As VCAM-1 is a key cell adhesion molecule involved in inflammation, the results confirm the clinical anti-inflammatory properties of hesperidin supplementation.

A placebo-controlled, randomized and double-blinded clinical trial was performed to evaluate the impact of hesperidin supplementation on the cognitive function of 37 senior healthy adults (60 - 81 years of age) [94]. In this trial, participants were assigned to drink of one of two dietary interventions twice per day. The interventions were $250 \mathrm{~mL}$ orange juice, containing hesperidin (549 $\mathrm{mg} / \mathrm{L})$ and narirutin $(60 \mathrm{mg} / \mathrm{L})$, or $250 \mathrm{~mL}$ orange juice with very little hesperi$\operatorname{din}(64 \mathrm{mg} / \mathrm{L})$ and narirutin $(10 \mathrm{mg} / \mathrm{L})$. After eight weeks, the cognitive function, executive function, and episodic memory of the high-hesperidin orange juice group was significantly better than low-hesperidin group $(\mathrm{p}<0.01)$. The study also found that the chronic consumption of hesperidin-rich juice significantly decreases diastolic blood pressure. This suggests that hesperidin-rich dietary interventions can prevent cognitive decline in neurodegenerative patients by increasing cerebral blood flow.

\section{Conclusion}

Dietary antioxidants have the potential to provide protection against skin photoaging. Results of in vitro, in vivo and human studies involving vitamin C, grape seed extract, and citrus bioflavonoids support the concept that antioxidant supplementation quenches UV-induced ROS generation in the skin. Further, these substances also reduce inflammation and expression of proteolytic enzyme which are involved in the premature aging of the skin. Each of these well-known antioxidants exhibits multiple other health benefits to the human body. Therefore, there is ample reason to recommend regular ingestion of these natural antioxidants as a means of maintaining skin health.

\section{Conflicts of Interest}

The authors declare no conflicts of interest regarding the publication of this paper.

\section{References}

[1] Klingman, L.H. (1986) Photoaging. Manifestations, Prevention, and Treatment. 
Dermatologic Clinics, 4, 517-528. https://doi.org/10.1016/S0733-8635(18)30815-5

[2] Farage, M.A., Miller, K.W., Elsner, P. and Maibach, H.L. (2008) Intrinsic and Extrinsic Factors in Skin Ageing: A Review. International Journal of Cosmetic Science, 30, 87-95. https://doi.org/10.1111/j.1468-2494.2007.00415.x

[3] Meinhardt, M., Krebs, R. anders, A., Heinrich, U. and Tronnier, H. (2008) Wavelength-Dependent Penetration Depths of Ultraviolet Radiation in Human Skin. Journal of Biomedical Optics, 14, Article ID: 044030. https://doi.org/10.1117/1.2957970

[4] Gilcrest, B.A. (2013) Photoaging. Journal of Investigative Dermatology, 133, E2-E6. https://doi.org/10.1038/skinbio.2013.176

[5] Braverman, I.M. and Fonferko, E. (1982) Studies in Cutaneous Aging: I. The Elastic Fiber Network. Journal of Investigative Dermatology, 78, 434-443. https://doi.org/10.1111/1523-1747.ep12507866

[6] Rittie, L. and Fisher, G.J. (2015) Natural and Sun-Induced Aging of Human Skin. Cold Spring Harbor Perspectives in Medicine, 5, a015370.

https://doi.org/10.1101/cshperspect.a015370

[7] Warren, R., Gartstein, V., Kligman, A.M., Montagna, W., Allendorf, R.A. and Ridder, G.M. (1981) Age, Sunlight, and Facial Skin: A Histologic and Quantitative Study. Journal of the American Academy of Dermatology, 25, 751-670.

https://doi.org/10.1016/S0190-9622(08)80964-4

[8] El-Domyati, M., Attia, S., Saleh, F., Brown, D., Birk, D.E., Gasparro, F., Ahmad, H. and Uitto, J. (2002) Intrinsic Aging vs. Photoaging: A Comparative Histopathological, Immunohistochemical, and Ultrastructural Study of Skin. Experimental Dermatology, 11, 398-405. https://doi.org/10.1034/j.1600-0625.2002.110502.x

[9] Hanson, K.M. and Simon, J.D. (1998) Epidermal Trans-Urocanic Acid and the UV-A-Induced Photoaging of the Skin. Proceedings of the National Academy of Sciences, 95, 10576-10578. https://doi.org/10.1073/pnas.95.18.10576

[10] Brenneisen, P., Wenk, J., Klotz, L.O., Wlaschek, M., Brivina, K., Krieg, T. and Scharffetter-Kochanek, K. (1998) Central Role of Ferrous/Ferric Iron in the Ultraviolet B Irradiation-Mediated Signaling Pathway Leading to Increased Interstitial Collagenase (Matrix-Degrading Metalloprotease (MMP)-1) and Stromelysin-1 (MMP-3) mRNA Levels in Cultured Human Dermal Fibroblasts. Journal of Biological Chemistry, 273, 5279-5287. https://doi.org/10.1074/jbc.273.9.5279

[11] Rijken, F. and Bruijnzeel, P.L.B. (2009) The Pathogenesis of Photoaging: The Role of Neutrophils and Neutrophil-Derived Enzymes. Journal of Investigative Dermatology Symposium Proceedings, 14, 67-72. https://doi.org/10.1038/jidsymp.2009.15

[12] Battie, C., Jitsukawa, S., Bernerd, F., Del Bino, S., Marionnet, C. and Vershoore, M. (2014) New Insights in Photoaging, UVA Induced Damage and Skin Types. Experimental Dermatology, 23, 7-12. https://doi.org/10.1111/exd.12388

[13] Holick, M.F., Chen, T.C., Lu, Z. and Sauter, E. (2007) Vitamin D and Skin Physiology: A D-Lightful Story. Journal of Bone and Mineral Research, 22, V28-V33. https://doi.org/10.1359/jbmr.07s211

[14] Singh, C.K., Mintie, C.A., Chhabra, G., Dakup, P.P., Ye, T., Yu and Ahmad, M.N. (2019) Chemoprotective Effects of Dietary Grape Powder on Ultraviolet B Radiation-Mediated Skin Carcinogenesis in SKH-1 Hairless Mice. The Journal of Investigative Dermatology, 139, 552-561. https://doi.org/10.1016/j.jid.2018.09.028

[15] Semba, R.D. (2012) The Discovery of the Vitamins. International Journal for Vitamin and Nutrition Research, 82, 310-315.

https://doi.org/10.1024/0300-9831/a000124 
[16] Dawood, M.A.O. and Koshio, S. (2018) Vitamin C Supplementation to Optimize Growth, Health and Stress Resistance in Aquatic Animals. Reviews in Aquaculture, 10, 334-350. https://doi.org/10.1111/raq.12163

[17] Wang, K., Jiang, H., Li, W., Qiang, M., Dong, T. and Li, H. (2018) Role of Vitamin C in Skin Diseases. Frontiers in Physiology, 9, 819. https://doi.org/10.3389/fphys.2018.00819

[18] The Nutrition Source. Vitamin C. https://www.hsph.harvard.edu/nutritionsource/vitamin-c

[19] Maxfield, L. and Crane, J.S. (2020) Vitamin C Deficiency. In: StatPearls, StatPearls Publishing, Treasure Island. https://www.ncbi.nlm.nih.gov/books/NBK493187

[20] National Institutes of Health (2019) Vitamin C. Fact Sheet for Consumers. https://ods.od.nih.gov/pdf/factsheets/VitaminC-Consumer.pdf

[21] Dormael, R.D., Bastien, P., Sextius, P., Gueniche, A., Ye, D., Tran, C., Chevalier, V., Gomes, C., Souverain, L. and Tricaud, C. (2019) Vitamin C Prevents Ultraviolet-Induced Pigmentation in Healthy Volunteers: Bayesian Meta-Analysis Results from 31 Randomized Controlled versus Vehicle Clinical Studies. The Journal of Clinical and Aesthetic Dermatology, 12, E53-E59.

[22] Petruk, G., Del Giudice, R., Rigano, M.M. and Monti, D.M. (2018) Antioxidants from Plants Protect against Skin Photoaging. Oxidative Medicine and Cellular Longevity, 2018, Article ID: 1454936. https://doi.org/10.1155/2018/1454936

[23] Gegotek, A., Jarocka-Karpowicz, I. and Skrzydlewska, E. (2020) Cytoprotective Effect of Ascorbic Acid and Rutin against Oxidative Changes in the Proteome of Skin Fibroblasts Cultured in a Three-Dimensional System. Nutrients, 12, 1074. https://doi.org/10.3390/nu12041074

[24] Hantke, B., Lahmann, C., Venzke, K., Fischer, T., Kocourek, A., Windsor, L.J., Bergemann, J., Stäb, F. and Tschesche, H. (2002) Influence of Flavonoids and Vitamins on the MMP and TIMP-Expression of Human Dermal Fibroblasts after UVA Irradiation. Photochemical \& Photobiological Sciences, 1, 826-833. https://doi.org/10.1039/B207731K

[25] Pullar, J.M., Carr, A.C. and Vissers, M.C.M. (2017) The Roles of Vitamin C in Skin Health. Nutrients, 9, 866. https://doi.org/10.3390/nu9080866

[26] Combs, G.F. (2008) The Vitamins: Fundamental Aspects in Nutrition and Health. 3rd Edition, Elsevier Academic Press, Amsterdam.

[27] Combs, G.F. and McClung, J.P. (2017) The Vitamins: Fundamental Aspects in Nutrition and Health. 5th Edition, Elsevier Academic Press, Amsterdam.

[28] Pawlowska, E., Szczepanska, J. and Blasiak, J. (2019) Pro- and Antioxidant Effects of Vitamin C in Cancer in Correspondence to Its Dietary and Pharmacological Concentrations. Oxidative Medicine and Cellular Longevity, 2019, Article ID: 7286737. https://doi.org/10.1155/2019/7286737

[29] Al-Niaimi, F. and Chiang, N.Y.Z. (2017) Topical Vitamin C and the Skin: Mechanisms of Action and Clinical Applications. The Journal of Clinical and Aesthetic Dermatology, 10, 14-17.

[30] Carr, A.C. and Maggini, S. (2017) Vitamin C and Immune Function. Nutrients, 9, 1211. https://doi.org/10.3390/nu9111211

[31] Naidu, K.A. (2003) Vitamin C in Human Health and Disease Is Still a Mystery? An Overview. Nutrition Journal, 2, 7. https://doi.org/10.1186/1475-2891-2-7

[32] Ravetti, S., Clemente, C., Brignone, S., Hergert, L., Allemandi, D. and Palma, S. 
(2019) Ascorbic Acid in Skin Health. Cosmetics, 6, 58. https://doi.org/10.3390/cosmetics6040058

[33] Gegotek, A., Bielawska, K., Biernacki, M., Zareba, I., Surazynski, A. and Skrzydlewska, E. (2017) Comparison of Protective Effect of Ascorbic Acid on Redox and Endocannabinoid Systems Interactions in in Vitro Cultured Human Skin Fibroblasts Exposed to UV Radiation and Hydrogen Peroxide. Archives of Dermatological Research, 309, 285-303. https://doi.org/10.1007/s00403-017-1729-0

[34] Tebbe, B., Wu, S., Geilen, C.C., Eberle, J. Kodelja, V. and Orfanos, C.E. (1997) L-Ascorbic Acid Inhibits UVA-Induced Lipid Peroxidation and Secretion of IL-1alpha and IL-6 in Cultured Human Keratinocytes In Vitro. Journal of Investigative Dermatology, 108, 302-306. https://doi.org/10.1111/1523-1747.ep12286468

[35] Selvaag, E., Petersen, A.B., Gniadecki, R., Thorn, T. and Wulf, H.C. (2002) Phototoxicity to Diuretics and Antidiabetics in the Cultured Keratinocyte Cell Line HaCaT: Evaluation by Clonogenic Assay and Single Cell Gel Electrophoresis Comet Assay. Photodermatology, Photoimmunology \& Photomedicine, 18, 90-95. https://doi.org/10.1034/j.1600-0781.2002.180206.x

[36] Shindo, Y., Witt, E. and Packer, L. (1993) Epidermis and Dermis and Their Responses to Ultraviolet Light. Journal of Investigative Dermatology, 100, 260-265. https://doi.org/10.1111/1523-1747.ep12469048

[37] Pauling, L., Willoughby, R., Reynolds, R., Blaisdell, B.E. and Lawson, S. (1982) Incidence of Squamous Cell Carcinoma in Hairless Mice Irradiated with Ultraviolet Light in Relation to Intake of Ascorbic Acid (Vitamin C) and of D, L-Alpha-Tocopheryl Acetate. International Journal for Vitamin and Nutrition Research. Supplement, 23, 53-82.

[38] Chakrabarti, R., Singh, M.K., Sharma, J.G. and Mittal, P. (2019) Dietary Supplementation of Vitamin C: And Effective Measure for Protection against UV-B Irradiation Using Fish as a Model Organism. Photochemical and Photobiological Sciences, 18, 224-231. https://doi.org/10.1039/C8PP00481A

[39] McArdle, F., Rhodes, L.E., Parslew, R., Jack, C.I.A., Friedmann, P.S. and Jackson, M.J. (2002) UVR-Induced Oxidative Stress in Human Skin in Vivo: Effects of Oral Vitamin C Supplementation. Free Radical Biology and Medicine, 33, 1355-1362. https://doi.org/10.1016/S0891-5849(02)01042-0

[40] Lauer, A.C., Groth, N., Haag, S.F., Darvin, M.E., Lademann, J. and Meinke, M.C. (2013) Dose-Dependent Vitamin C Uptake and Radical Scavenging Activity in Human Skin Measured with in Vivo Electron Paramagnetic Resonance Spectroscopy. Skin Pharmacology and Physiology, 26, 147-154. https://doi.org/10.1159/000350833

[41] Eberlein-König, B., Placzek, M. and Przybilla, B. (1998) Protective Effect against Sunburn of Combined Systemic Ascorbic Acid (Vitamin C) and D-Alpha-Tocopherol (Vitamin E). Journal of the American Academy of Dermatology, 38, 45-48. https://doi.org/10.1016/S0190-9622(98)70537-7

[42] Placzek, M., Gaube, S., Kerkmann, U., Gilbertz, K.P., Herzinger, T., Haen, E. and Przybilla, B. (2005) Ultraviolet B-Induced DNA Damage in Human Epidermis Is Modified by the Antioxidants Ascorbic Acid and D-Alpha-Tocopherol. Journal of Investigative Dermatology, 124, 304-307. https://doi.org/10.1111/j.0022-202X.2004.23560.x

[43] Rodriguez-Perez, C., Garcia-Villanova, B., Guerra-Hernandez, E. and Verardo, V. (2019) Grape Seeds Proanthocyanidins: An Overview of in Vivo Bioactivity in Animal Models. Nutrients, 11, 2435. https://doi.org/10.3390/nu11102435 
[44] De Freitas, V.A.P., Glories, Y., Bourgeois, G. and Vitry, C. (1998) Characterisation of Oligomeric and Polymeric Procyanidins from Grape Seeds by Liquid Secondary Ion Mass Spectrometry. Phytochemistry, 49, 1435-1441. https://doi.org/10.1016/S0031-9422(98)00107-1

[45] Zhang, H, Liu, S., Li, L., Liu, S., Liu, S., Mi, J. and Tian, G. (2016) The Impact of Grape Seed Extract Treatment on Blood Pressure Changes: A Meta-Analysis of 16 Randomized Controlled Trials. Medicine, 95, e4247. https://doi.org/10.1097/MD.0000000000004247

[46] Asbaghi, O., Nazarian, B., Reiner, Z., Amirani, E., Kolahdooz, F., Chamani, M. and Asemi, Z. (2020) The Effects of Grape Seed Extract on Glycemic Control, Serum Lipoproteins, Inflammation, and Body Weight: A Systemic Review and Meta-Analysis of Randomized Controlled Trials. Phytotherapy Research, 34, 239-253. https://doi.org/10.1002/ptr.6518

[47] Gupta, M., Dey, S., Marbaniang, D., Pal, P., Ray, S. and Mazumder, B. (2020) Grape Seed Extract: Having a Potential Health Benefits. Journal of Food Science and Technology, 57, 1205-1215. https://doi.org/10.1007/s13197-019-04113-w

[48] Songsermsakul, P., Pornphairin, E. and Porasuphantana, S. (2013) Comparison of Antioxidant Activity of Grape Seed Extract and Fruits Containing High $\beta$-Carotene, Vitamin C, and E. International Journal of Food Properties, 16, 643-648. https://doi.org/10.1080/10942912.2011.561462

[49] Perde-Schrepler, M., Chereches, G., Brie, I., Tatomir, C., Postescu, I.D., Soran, L. and Filip, A. (2013) Grape Seed Extract as Photochemopreventive Agent against UVB-Induced Skin Cancer. Journal of Photochemistry and Photobiology B, 118, 16-21. https://doi.org/10.1016/j.jphotobiol.2012.10.008

[50] Decean, H., Fischer-Fodor, E., Tatomir, C., Perde-Schrepler, M., Somfalean, L., Burz, C., Hodor, T., Orasan, R. and Virag, P. (2016) Vitis vinifera Seeds Extract for the Modulation of Cytosolic Factors BAX- $\alpha$ and NF- $\kappa \beta$ Involved in UVB-Induced Oxidative Stress and Apoptosis of Human Skin Cells. Clujul Medical, 89, 72-81. https://doi.org/10.15386/cjmed-508

[51] Vaid, M., Sharma, S.D. and Katiyar, S.K. (2010) Proanthocyanidins Inhibit Photocarcinogenesis through Enhancement of DNA Repair and Xeroderma Pigmentosum Group A-Dependent Mechanism. Cancer Prevention Research, 3, 621-629. https://doi.org/10.1158/1940-6207.CAPR-10-0137

[52] Sharma, S.D. and Katiyar, S.K. (2010) Dietary Grape Seed Proanthocyanidins Inhibit UVB-Induced Cyclooxygenase-2 Expression and Other Inflammatory Mediators in UVB-Exposed Skin and Skin Tumors of SKH-1 Hairless Mice. Pharmaceutical Research, 27, 1092-1102. https://doi.org/10.1007/s11095-010-0050-9

[53] Gilchrest, B.A. (1996) A Review of Skin Aging and Its Medical Therapy. British Journal of Dermatology, 135, 867-875. https://doi.org/10.1046/j.1365-2133.1996.d01-1088.x

[54] Wang, C., Wang, Y., Yu, M., Chen, C., Xu, L. Cao, Y. and Qi, R. (2017) Grape-Seed Polyphenols Play a Protective Role in Elastase-Induced Abdominal Aortic Aneurysm in Mice. Scientific Reports, 7, Article No. 9402. https://doi.org/10.1038/s41598-017-09674-4

[55] Mittal, A., Elmets, C.A. and Katiyar, S.K. (2003) Dietary Feeding of Proanthocyanidins from Grape Seeds Prevents Photocarcinogenesis in SKH-1 Hairless Mice: Relationship to Decreased Fat and Lipid Peroxidation. Carcinogenesis, 24, 1379-1388. https://doi.org/10.1093/carcin/bgg095

[56] Sharma, S.D., Meeran, S.M. and Katiyar, S.K. (2007) Dietary Grape Seed Proantho- 
cyanidins Inhibit UVB-Induced Oxidative Stress and Activation of Mitogen-Activated Protein Kinases and Nuclear Factor-KB Signaling in in Vivo SKH-1 Hairless Mice. Molecular Cancer Therapeutics, 6, 995-1005. https://doi.org/10.1158/1535-7163.MCT-06-0661

[57] Sharma, S.D. and Katiyar, S.K. (2006) Dietary Grape-Seed Proanthocyanidin Inhibition of Ultraviolet B-Induced Immune Suppression Is Associated with Induction of IL-12. Carcinogenesis, 27, 95-102. https://doi.org/10.1093/carcin/bgi169

[58] Vaid, M., Singh, T., Li, A., Katiyar, N., Sharma, S., Elmets, C.A., Xu, H. and Katiyar, S.K. (2012) Proanthocyanidins Inhibit UV-Induced Immunosuppression through IL-12-Dependent Stimulation of CD8+ Effector T Cells and Inactivation of CD4+ T Cells. Cancer Prevention Research, 4, 238-247. https://doi.org/10.1158/1940-6207.CAPR-10-0224

[59] Yamakoshi, J., Otsuka, F., Sano, A., Tokutake, S., Saito, M., Kikuchi, M. and Kubota, Y. (2003) Lightening Effect on Ultraviolet-Induced Pigmentation of Guinea Pig Skin by Oral Administration of Proanthocyanidin-Rich Extract from Grape Seeds. Pigment Cell Research, 16, 629-638. https://doi.org/10.1046/j.1600-0749.2003.00093.x

[60] Yamakoshi, J., Sano, A., Tokutake, S., Saito, M., Kikuchi, M., Kubota, Y., Kawachi, Y. and Otsuka, F. (2004) Oral Intake of Proanthocyanidin-Rich Extract from Grape Seed Improves Chloasma. Phytotherapy Research, 18, 895-899. https://doi.org/10.1002/ptr.1537

[61] Nuttall, S.L., Kendell, M.J., Bombardelli, E. and Morazzoni, P. (1998) An Evaluation of the Antioxidant Activity of a Standardized Grape Seed Extract, Leucoselect. Journal of Clinical Pharmacy and Therapeutics, 23, 385-389. https://doi.org/10.1046/j.1365-2710.1998.00180.x

[62] Lee, H.J., Ahn, H.S. and Bae, H.S. (2012) Antioxidant Status of Serum by the Wellness Index of the Skin in Middle Aged Women. Korean Journal of Aesthetics and Cosmetology, 10, 15-23.

[63] Costa, A., Lindmark, L., Arruda, L.H.F., Assumpcao, E.C., Ota, F.S., Pereira, M.D.O. and Langen, S.S.B. (2011) Clinical, Biometric and Ultrasound Assessment of the Effects of Daily Use of a Nutraceutical Composed of Lycopene, Acerola Extract, Grape Seed Extract and Biomarine Complex in Photoaged Human Skin. Anais Brasileiros de Dermatologia, 87, 52-61. https://doi.org/10.1590/S0365-05962012000100006

[64] Costa, A., Pereira, E.S.P., Assumpcao, E.C., et al. (2015) Assessment of Clinical Effects and Safety of an Oral Supplement Based on Marine Protein, Vitamin C, Grape Seed Extract, Zinc, and Tomato Extract in the Improvement of Visible Signs of Skin Aging in Men. Clinical, Cosmetic and Investigational Dermatology, 8, 319-328. https://doi.org/10.2147/CCID.S79447

[65] Doumalin, M., Gaudout, D. and Lemaire, B. (2016) Clinical Effects of an Oral Supplement Rich in Antioxidants on Skin Radiance in Women. Clinical, Cosmetic and Investigational Dermatology, 9, 315-324. https://doi.org/10.2147/CCID.S118920

[66] Skovgaard, G.R.L., Jensen, A.S. and Sigler, M.L. (2006) Effect of a Novel Dietary Supplement on Skin Aging in Post-Menopausal Women. European Journal of Clinical Nutrition, 60, 1201-1206. https://doi.org/10.1038/sj.ejcn.1602438

[67] Bocco, A., Cuvelier, M.E., Richard, H. and Berset, C. (1998) Antioxidant Activity and Phenolic Composition of Citrus Peel and Seed Extracts. Journal of Agricultural and Food Chemistry, 46, 2123-2129. https://doi.org/10.1021/jf9709562

[68] Garg, A., Garg, S., Zaneveld, L.J.D. and Singla, A.K. (2001) Chemistry and Pharmacology of the Citrus Bioflaconoid Hesperidin. Phytotherapy Research, 15, 655-669. 
https://doi.org/10.1002/ptr.1074

[69] Panche, A.N., Diwan, A.D. and Chandra, S.R. (2016) Flavonoids: An Overview. Journal of Nutritional Science, 5, E47. https://doi.org/10.1017/jns.2016.41

[70] Wang, T.Y., Li, Q. and Bi, K.S. (2018) Bioactive Flavonoids in Medicinal Plants: Structure, Activity and Biological Fate. Asian Journal of Pharmaceutical Sciences, 13, 12-23. https://doi.org/10.1016/j.ajps.2017.08.004

[71] Cerqueira e Silva, L.C.R., David, J.M., Borges, R.S.Q., Ferreira, S.L.C., David, J.P., Reis, P.S. and Bruns, R.E. (2014) Determination of Flavanones in Orange Juices Obtained from Different Sources by HPLC/DAD. Journal of Analytical Methods in Chemistry, 2014, Article ID 296838. https://doi.org/10.1155/2014/296838

[72] Castro-Vazquez, L., Alañón, M.E., Rodríguez-Robledo, V., Pérez-Coello, M.S., Hermosín-Gutierrez, I., Díaz-Maroto, M.C., Jordán, J., Galindo, M.F. and Arroyo-Jiménez, M.M. (2016) Bioactive Flavonoids, Antioxidant Behaviour, and Cytoprotective Effects of Dried Grapefruit Peels (Citrus paradisi Macf.). Oxidative Medicine and Cellular Longevity, 2016, Article ID: 8915729.

https://doi.org/10.1155/2016/8915729

[73] Sun, Y., Wang, J., Gu, S., Liu, Z., Zhang, Y. and Zhang, X. (2010) Simultaneous Determination of Flavonoids in Different Parts of Citrus reticulate "Chachi" Fruit by High Performance Liquid Chromatography-Photodiode Array Detection. Molecules, 15, 5378-5388. https://doi.org/10.3390/molecules15085378

[74] Tripoli, E., Guardia, M.L., Giammanco, S., Majo, D.D. and Giammanco, G. (2007) Citrus Flavonoids: Molecular Structure, Biological Activity and Nutritional Properties: A Review. Food Chemistry, 104, 466-479.

https://doi.org/10.1016/j.foodchem.2006.11.054

[75] Kim, H., Jeong, Y., Kim, J. and Par, Y. (2018) 3,5,6,7,8,3,4'-Heptamethoxyflavone, a Citrus Flavonoid, Inhibits Collagenase Activity and Induces Type I Procollagen Synthesis in HDFn Cells. International Journal of Molecular Sciences, 19, 620. https://doi.org/10.3390/ijms19020620

[76] Li, M., Lin, X.F., Lu, J., Zhou, B.R. and Luo, D. (2016) Hesperidin Ameliorates UV Radiation-Induced Skin Damage by Abrogation of Oxidative Stress and Inflammatory in HaCaT Cells. Journal of Photochemistry and Photobiology B: Biology, 165, 240-245. https://doi.org/10.1016/j.jphotobiol.2016.10.037

[77] Hewage, S.R.K.M., Piao, M.J., Kang, K.A., Ryu, Y.S., Han, X., Oh, M.C., Jung, U., Kim, I.G. and Hyun, J.W. (2016) Hesperidin Attenuates Ultraviolet B-Induced Apoptosis by Mitigating Oxidative Stress in Human Keratinocytes. Biomolecules \& Therapeutics, 24, 312-319. https://doi.org/10.4062/biomolther.2015.139

[78] Kim, C.J. and Cho, S.K. (1991) Pharmacological Activities of Flavonoids (III) Structure-Activity Relationships of Flavonoids in Immunosuppression. Archives of Pharmacal Research 14, 147-159. https://doi.org/10.1007/BF02892020

[79] Bae, J.T., Ko, J., Kim, G.B., Pyo, H.B. and Lee, G.S. (2012) Protective Effects of Fermented Citrus Unshiu Peel Extract against Ultraviolet-a-Induced Photoageing in Human Dermal Fibrobolasts. Phytotherapy Research, 26, 1851-1856.

https://doi.org/10.1002/ptr.4670

[80] Proteggente, A.R., Basu-Modak, S. and Kuhnle, G. (2003) Hesperidin Glucuronide, a Photoprotective Agent Arising from Flavonoid Metabolism in Human Skin Fibroblasts. Photochemistry and Photobiology, 78, 256-261. https://doi.org/10.1562/0031-8655(2003)078<0256:HGAPAA >2.0.CO;2

[81] Prasanth, M.I., Gayathri, S., Bhaskar, J.B., Krishnan, V. and Balamurugan, K. (2019) Analyzing the Synergistic Effects of Antioxidants in Combating Photoaging Using 
Model Nematode, Caenorhabditis elegans. Photochemistry Photobiology, 96, 139-147. https://doi.org/10.1111/php.13167

[82] Jung, S.K., Ha, S.J., Jung, C.H., Kim, Y.T., Lee, H.K., Kim, M.O., Lee, M.H., Mottamal, M., Bode, A.M., Lee, K.W. and Dong, Z. (2016) Naringenin Targets ERK2 and Suppresses UVB-Induced Photoaging. Journal of Cellular and Molecular Medicine, 20, 909-919. https://doi.org/10.1111/jcmm.12780

[83] Das, R.N., Balupillai, A., David, E., Santhoshkumar, M. and Muruhan, S. (2020) Naringin, a Natural Flavonoid, Modulates UVB Radiation-Induced DNA Damage and Photoaging by Modulating NER Repair and MMPS Expression in Mouse Embryonic Fibroblast Cells. Journal of Environmental Pathology, Toxicology and Oncology, 39, 191-199. https://doi.org/10.1615/JEnvironPatholToxicolOncol.2020031914

[84] Zhou, L., Wang, L., Zhang, J., Li, J., Bai, S. and Ma, J. (2019) Didymin Improves UV Irradiation Resistance in C. elegans. PeerJ, 6, e6218.

https://doi.org/10.7717/peerj.6218

[85] Lee, H.J., Im, A., Kim, S., Kang, H., Lee, J.D. and Chae, S. (2018) The Flavonoid Hesperidin Exerts Anti-Photoaging Effect by Downregulating Matrix Metalloproteinase (MMP)-9 Expression via Mitogen Activated Protein Kinase (MAPK)-Dependent Signaling Pathways. BMC Complementary Medicine and Therapies, 18, 39. https://doi.org/10.1186/s12906-017-2058-8

[86] Stanisic, D., Liu, L.H.B., Santos R.V., Costa, A.F., Durán, N. and Tasic, L. (2020) New Sustainable Process for Hesperidin Isolation and Anti-Ageing Effects of Hesperidin Nanocrystals. Molecules, 25, 4534.

https://doi.org/10.3390/molecules25194534

[87] Tamaru, E., Watanabe, M. and Nomura, Y. (2020) Dietary Immature Citrus Unshiu Alleviates UVB-Induced Photoaging by Suppressing Degradation of Basement Membrane in Hairless Mice. Heliyon, 6, e04218.

https://doi.org/10.1016/j.heliyon.2020.e04218

[88] Martinez, R.M., Pinho-Ribeiro, F.A., Steffen, V.S., Silva, T.C.C., Caviglione, C.V., Bottura, C., Fonseca, M.J.V., Vicentini, F.T.M.C., Vignoli, J.A., Baracat, M.M., Georgetti, S.R., Verri Jr., W.A. and Casagrande, R. (2016) Topical Formulation Containing Naringenin: Efficacy against Ultraviolet B Irradiation-Induced Skin Inflammation and Oxidative Stress in Mice. PLOS ONE, 11, e0146296.

https://doi.org/10.1371/journal.pone.0146296

[89] Tirkey, N., Pilkhwal, S., Kuhad, A. and Chopra, K. (2005) Hesperidin, a Citrus Bioflavonoid, Decreases the Oxidative Stress Produced by Carbon Tetrachloride in Rat Liver and Kidney. BMC Pharmacology and Toxicology, 5, 2.

https://doi.org/10.1186/1471-2210-5-2

[90] Jovanovic, S.V., Steenken, S., Tosic, M., Marjanovic, B. and Simic, M.G. (1994) Flavonoids as Antioxidants. Journal of the American Chemical Society, 116, 4846-4851. https://doi.org/10.1021/ja00090a032

[91] Meneguzzo, F., Ciriminna, R., Zabini, F. and Pagliaro, M. (2020) Review of Evidence Available on Hesperidin-Rich Products as Potential Tools against COVID-19 and Hydrodynamic Cavitation-Based Extraction as a Method of Increasing Their Production Francesco. Processes, 8, 549. https://doi.org/10.3390/pr8050549

[92] Pérez-Sánchez, A., Barrajón-Catalána, E., Caturla, N., Castillo, J., Benavente-García, O., Alcaraz, M. and Micol, V. (2014) Protective Effects of Citrus and Rosemary Extracts on UV-Induced Damage in Skin Cell Model and Human Volunteers. Journal of Photochemistry and Photobiology B: Biology, 136, 12-18. https://doi.org/10.1016/j.jphotobiol.2014.04.007 
[93] Lorzadeh, E., Ramezani-Jolfaie, N., Mohammadi, M., Khoshbakht, Y. and Salehi-Abargouei, A. (2019) The Effect of Hesperidin Supplementation on Inflammatory Markers in Human Adults: A Systematic Review and Meta-Analysis of Randomized Controlled Clinical Trials. Chemico-Biological Interactions, 307, 8-15. https://doi.org/10.1016/j.cbi.2019.04.016

[94] Kean, R.J., Lamport, D.J., Dodd, G.F., Freeman, J.E., Williams, C.M., Ellis, J.A., Butler, L.T. and Spencer, J.P. (2015) Chronic Consumption of Flavanone-Rich Orange Juice Is Associated with Cognitive Benefits: An 8-wk, Randomized, Double-Blind, Placebo-Controlled Trial in Healthy Older Adults. The American Journal of Clinical Nutrition, 101, 506-514. https://doi.org/10.3945/ajcn.114.088518 